Research Article

www.jestr.org

\title{
Analysis of Anchoring Mechanism of Fully Grouted Prestressed Anchor
}

\author{
WEN Zhi-jie ${ }^{1,2,3,4^{*}}$, ZHU Zhu-wu ${ }^{1,2}$, Chen Lian-jun ${ }^{1,2}$ and Wen Jin-hao ${ }^{1,2}$ \\ ${ }^{1}$ State Key Laboratory of Mining Disaster Prevention and Control Co-founded by Shandong Province and the Ministry of Science and \\ Technology, Shandong University of Science and Technology, Qingdao, Shandong 266590, China \\ ${ }^{2}$ Shandong Provincal Key Laboratory of Mining Disaster Prevention and Control, Shandong University of Science and Technology, \\ Qingdao, Shandong 266590, China; \\ ${ }^{3}$ Research Center of Geotechnical and Structural Engineering, Shandong University, Jinan, Shandong, China \\ ${ }^{4}$ Department of Civil and Environmental Engineering, Aalto University, ESPOO, 00076, Finland
}

Received 22 October 2013; Accepted 20 January 2014

\begin{abstract}
Some researchers have been carried out on analysis of the influence of the full grouted prestressed anchor shape of borehole wall on its carrying capacity. Based on the self-affine fractal feature of anchor borehole wall structural plane, the relation equation among structural plane shear strength, liquid injection pressure, tensile load and structural plane fractal dimension $\mathrm{D}$ was built, the instability judgment criterion of anchoring bearing strata and rock structural plane was determined, the solving equations of disintegrated rock support density were derived. Based on the experimental results, the theoretical basis of support design under the disintegrated rock condition was offered.
\end{abstract}

Keywords: fractal dimensions, wholly grouted, structural mode, anchoring mechanism

\section{Introduction}

With the increasing of mining depth, the mining conditions become complicated and the in-situ stress become bigger, which change the mechanical properties of rock mass (e.g., structure, strength) [1],[2],[3]. Under this condition, the surrounding rock of the roadway is characteristic of obvious soft rock properties, more broken structures, and larger deformations. So it has to be faced with some engineering problems including hard supporting, big repair work, high maintenance cost and some safety problems, which threaten the safety and high-efficiency of deep resource[4],[5],[6].

Roadway support and maintenance technology is a key technique in coal mining and roadway supporting technology. Safe and effective roadway supporting technology is the necessary condition to guarantee the coal mine high yield and efficient [7], [8], [9], [10]. The roadway support technology in coal mine mining process plays a very important role, so the scholars at home and abroad in the research and exploration of roadway support technology has done a lot of research work, The supporting technology of roadway could become more and more perfect[11],[12],[13].

The resistance of rockbolt and anchoring effect concern success or failure of engineering effect. Now, the common use of anchoring structure in geotechnical engineering is prestressed anchor and non-prestressed anchor [14], [15], [16]. It commonly use full grouted anchor, often used fullygrouted bolt, but without supporting anchor stress in time is the disadvantage of fully-grouted[17],[18],[19]. The

*E-mail address: sdust0532@gmail.com

ISSN: 1791-2377 @ 2014 Kavala Institute of Technology. All rights reserved. components of prestressed anchor are anchoring section, free section and anchor head, but the stress loss is hard. But it is hard to support broken rock of conventional anchoring support system [20], [21], [22].

In order to find a solution to the current anchoring structure, a new fully grouted anchor was studied which was composed of anchoring body, end anchorage component, filter opening, fixed tube and loading component.

A new type of roadway supporting technology that injection molding and three-dimensional stress bolt supporting technology was raised [23], [24], [25]. It can be applied to the roadway that composed of a variety of surrounding rock, especially the weak rock roadway. The injection molding and three-dimensional stress bolt advantage is that the surrounding rock can be anchored initiatively in the length of the direction, In addition when flexible outer lose efficacy, it can be used as rigid anchor to support tunnel influenced various environmental factors. The subsequent deformation happened with the deformation of surrounding rock, but the anchoring force was not affected. It is not need to maintain roadway secondarily, so it can save a lot of money according to coal enterprises.

According to the new situation, new problems of coal mines in China, flexible materials can be widely applied to support roadway [26], [27], [28]. The main principle is to impose radial pressure on surrounding rock, which can improve the mechanical property of surrounding rock, so the stability of surrounding rock will be improved significantly. Meanwhile, the bolt can raise the bearing capacity for the tensile property of bolt. Therefore, with the tensile property and offering radial pressure characteristics, the bolt can 
WEN Zhi-jie, ZHU Zhu-wu, Chen Lian-jun and Wen Jin-hao/

Journal of Engineering Science and Technology Review 7 (1) (2014) 15 - 20

improve the resistance to plastic deformation capacity, it can keep surrounding rock remaining triaxial compression state, while this feature that makes them different to other like products.

The injection molding and three dimensional stress bolt which is a new structure and anchoring mechanism bolt is the research foundation of flexible supporting equipment [29], [30]. It was proposed by professor Song zhenqi who is a Chinese Academy of Sciences. When using the bolt, the support system ideas changed significantly, the stability of surrounding rock was raised significantly.

\section{Influence factors for the stability of surrounding rock}

According to the analysis of the failure model and mechanism of surrounding rock mentioned above, because of the incredible complexity of geotechnical engineering, it is impossible that all the influence factors related to the stability of surrounding rock and surrounding rock pressure are considered. From the perspective of engineering projects, the predominant and controlling factors are given below [31].

(1) Rock mass strength of surrounding rock.

After excavation, the surround rock is not only a transfer media of applied load, but also a bearing structure to carry the applied load and protect the roadway space. So, the value of rock mass strength of surrounding rock directly affects the bearing capacity of the surrounding rock structure. That is, the stability of surrounding rock is not only related to the roof strength, but also to the floor strength and the rock mass strength of two sides' roadway.

\section{(2) In-situ stress.}

The in-situ stress including gravity stress and tectonic stress is an essential force causing rock deformation and instability failure. For the tectonic stress, it is hard to estimate and ensure its value, so it is ignored in the analysis procedure of surrounding rock stability. For the gravity type in-situ stress, mining depth can be used to reflect the stability of surrounding rock. For the roadway with same surrounding rock and different mining depth, their stress status and their responding behaviors are different from each other. The vertical pressure is proportional to the height of overlying rock mass. So, the higher the mining depth is, the harder the support of roadway is.

\section{(3) Integrity of rock mass.}

Rock mass contains geological weak plane and structural plane, including stratifications, joints, fracture and weak intercalated layer, in different degree. And, the geotechnical engineering can either be good or bad largely depending on not only many kinds of the weak structural planes and their fillers induced by the various of geological factors and geological conditions, but also their space distribution state including group count of structural plane, space, and number of joints in unit volume of rock mass. Those flaws largely weaken the integrity of rock mass, decrease its strength, and low directly its stability. So, the integrity index of rock mass is an important characterization factor for the roadway projects.

\section{(4) Underground water.}

The effect of underground water on surrounding rock quality is to change the engineering properties by hydraulic action, physical process and chemical action. The effects are mainly reflected in: increasing the bearing pressure of the supporting structure; decreasing the rock strength and causing instability failure; accelerating dissolution in longterm effect; generating leakage and gush that affects the excavation and normal use of roadway; softening surrounding rock, especially for the soft rock. The effect is usually expressed by impact factor.

(5) Sectional shape and size of roadway.

The sectional shape of roadway mainly includes rectangle, inclined top echelon and echelon, so the effect of the shape on the roadway stability can be reflected by roadway span. The bigger the roadway span is, the less stability the roadway is. The sectional size of roadway is closely related to the deformation of surrounding rock. Adding the roadway width will increase roof-to-floor convergence.

\section{Anchor structure}

The new technology that Rubber material was applied to mine support areas has not been described at home and abroad. The Fully grouted prestressed anchor structure is shown in Figure 1.

\section{(1)filler mouth}

Liquid medium will be injected into the rubber bolt via filler mouth by injection system. Injection quill pulled out when the pressure inside the rubber bolt met the requirements, the pressure inside the rubber bolt could compact the top edge of filler mouth to the center, then the filler mouth will be closed implicitly to keep anchor within the appropriate pressure. The closed effect is proportional to the pressure inside the rubber bolt.

\section{(2)anchor rod body}

The major structure of bolt is Hollow rebar of which is used to bear the drawing force.

\section{(3)expansion body}

The expansion body was composed of high elasticity and low modulus of elasticity rubber material. The expansion body will expand with the pressure inside the bolt increasing. After the anchor expansion, it will be good contact the surrounding rock, then the anchor effected.

\section{(4)protective jacket}

The protective jacket was used to confine the expansion body's expansion rate in reasonable range.

\section{(5)fixed sleeve}

The fixed sleeve was used to seat the anchor body and expansion body, then confined space in which the grout injection was injected was formed.

\section{(6)End anchorage parts}

By injection molding or mechanical action, the end anchorage parts was bulked to solidify the bolt in the deep surrounding rock. 
WEN Zhi-jie, ZHU Zhu-wu, Chen Lian-jun and Wen Jin-hao/

Journal of Engineering Science and Technology Review 7 (1) (2014) 15 - 20

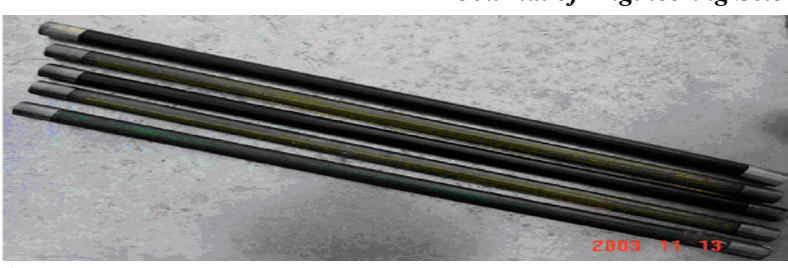

a)

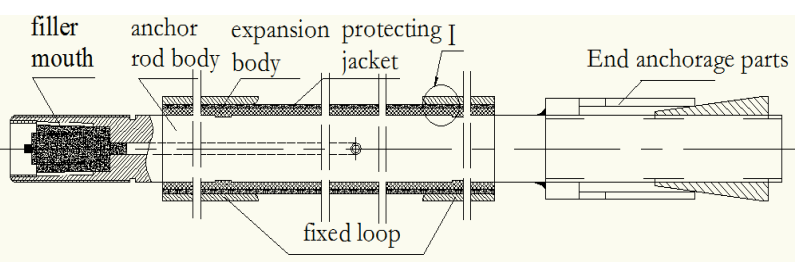

b)

Fig. 1. Anchor structure

\section{Mechanism of bolt force}

In order to study the interactional mechanism of loading bolt and anchoring body interface, the rational mechanical model should be built firstly. For the anchoring force was transmitted through loading component to anchoring body, so the main emphasis should be focused on interface properties of loading component and anchoring body.

\subsection{Geometric properties of anchoring body interface}

The surface contour line of joints can be considered as a fractal curve, the pore wall has waveform structure, its test results are shown in table1 and Fig.2.

\subsection{Mechanism of bolt force}

(1) Defining injecting liquid pressure

Anchoring force depends on the binding extent of anchor and anchoring structure, the working structure is shown in Fig3 (a).

Taking a concave-convex unit as a free body (Fig.3(b)), anchoring force direction assumed from left to right, the surface of concave-convex unit is nearly horizontal, the equilibrium equation of concave-convex unit is as follows:

$\left\{\begin{array}{l}\tau_{3}=\sigma_{3} \tan \phi_{b i}+C_{b i} \\ \sigma_{3}=\lambda \cdot \gamma H\end{array}\right.$

In which $\phi_{b i}$ is angle of internal friction, $\mathrm{C}_{\mathrm{bi}}$ is cohesion, $\lambda$ is coefficient of lateral pressure, $H$ is buried depth and $\gamma$ is unit weight.

The invalid place of anchor may lies at interface $\mathrm{ABC}$ or shearing surface $\mathrm{BC}$. The equilibrium equation with effective anchor is as follows:

$$
\sum X=0
$$$$
\left\{\begin{array}{l}
\tau_{3}=\tau_{1} \cos \alpha_{i}+\tau_{2} \cos \alpha_{i}=2 \tau \cos \alpha_{i} \\
\tau_{3}=\sigma_{3} \tan \phi_{b}+C \\
\tau=\sigma_{n} \tan \left[\phi_{b}+J_{R C} \cdot \lg \left(J_{C S} / \sigma_{n}\right)\right]
\end{array}\right.
$$

In favor of calculating, we consider angle of concaveconvex unit $\alpha_{i}=\alpha$.

$$
\sigma_{3} \tan \phi_{b}+C=2 \cos \alpha \cdot \tan \left[\phi_{b}+J_{R C} \cdot \lg \left(J_{C S} / \sigma_{n}\right)\right]
$$

$$
\sigma_{n}=\frac{J_{C S}}{10}=f_{1}\left(D, C, \phi_{b}, \alpha\right)
$$

To the known condition, $\mathrm{f}_{1}\left(\mathrm{D}, \mathrm{C}, \phi_{\mathrm{b}}, \mathrm{a}\right)$ is a constant value, setting it as $\mathrm{q}$.

When $\sigma_{\mathrm{n}}<\mathrm{q}$, the disequilibrium place located between lading component and rock mass surface;

When $\sigma_{\mathrm{n}}>\mathrm{q}$, the disequilibrium place located at rock mass surface.

Tab. 1 Statistic data about undulation of hole wall in test section

\begin{tabular}{cllll}
\hline $\begin{array}{c}\text { Rock } \\
\text { mass }\end{array}$ & $\begin{array}{l}\text { Length } \\
/ \mathrm{mm}\end{array}$ & $\begin{array}{l}\text { maximum difference } \\
\text { fluctuations } / \mathrm{mm}\end{array}$ & $\begin{array}{l}\text { average difference } \\
\text { fluctuations value } \\
/ \mathrm{mm}\end{array}$ & $\begin{array}{l}\text { average } \\
\text { wavelength } \\
/ \mathrm{mm}\end{array}$ \\
\hline sandstone & 150 & 0.8760 & 0.5767 & 74.9 \\
limestone & 220 & 1.2906 & 0.7526 & 61.3 \\
\hline
\end{tabular}

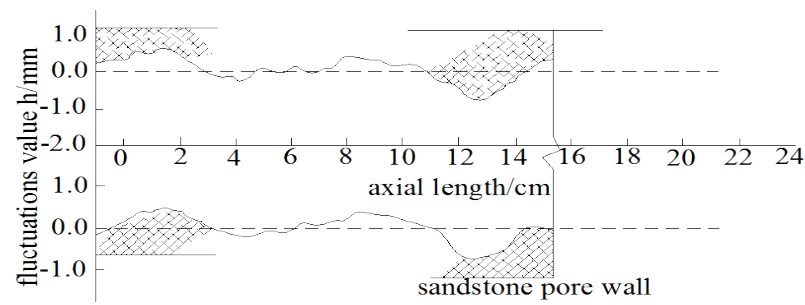

a) sandstone

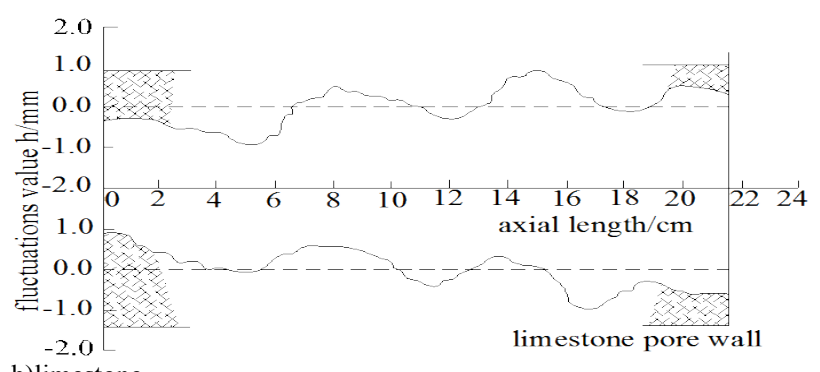

b) limestone

Fig.2 Shape of hole wall

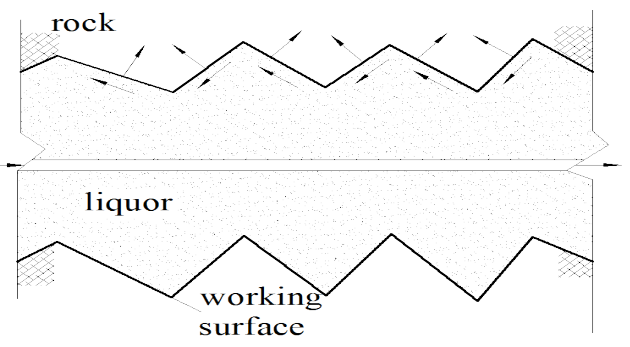

a)

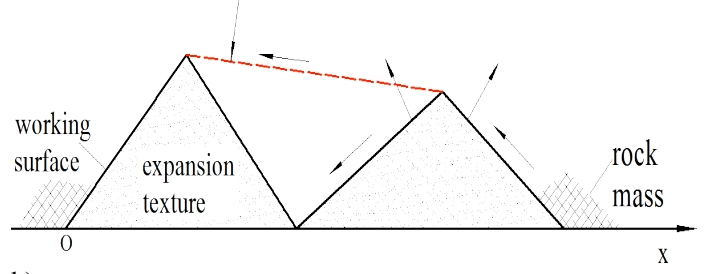

b)

Fig.3 Full grouted prestressed anchor bearing sketh

(2) Defining loading capacity

The fully grouted anchor load transmitted between loading component and rock mass interface. 
WEN Zhi-jie, ZHU Zhu-wu, Chen Lian-jun and Wen Jin-hao/

Journal of Engineering Science and Technology Review 7 (1) (2014) 15 - 20

The anchor calculating formula of loading capacity is as follows

$$
\begin{aligned}
& P=R+Q+\int_{0}^{L_{X}} 2 \pi r \cdot \tau d x=R+ \\
& 2 \pi r L_{X} \sigma_{n} \tan \left[\phi_{b}+J_{R C} \cdot \lg \left(J_{C S} / \sigma_{n}\right)\right]+\int_{0}^{L_{0}} 2 \pi r \tau_{3} d y \\
& =R+\left(A+B \tan \left[\phi_{b}+J_{R C} \cdot \lg \left(J_{C S} / \sigma_{n}\right)\right]\right) \varepsilon^{1-D} \\
& =R+f_{1}(D)
\end{aligned}
$$

In which $\mathrm{d}$ is bolt diameter, $\mathrm{r}$ is average diameter, $\sigma_{3}$ is normal stress of concave-convex unit, $\tau_{3}$ is shearing strength of concave-convex unit, $\varepsilon$ is measurement scale, 1 is a constant value, $\mathrm{R}$ is initial prestress, $\mathrm{Q}$ is shear strength.

$$
\begin{aligned}
& \text { 1) } J_{C S}<\sigma_{n} \\
& P=R+\left(A+B \tan \phi_{b}\right) \varepsilon^{1-D}
\end{aligned}
$$

According to an actual condition, the loading capacity is shown in Fig.4, relation curve of loading capacity and concave-convex unit is shown in Fig.5

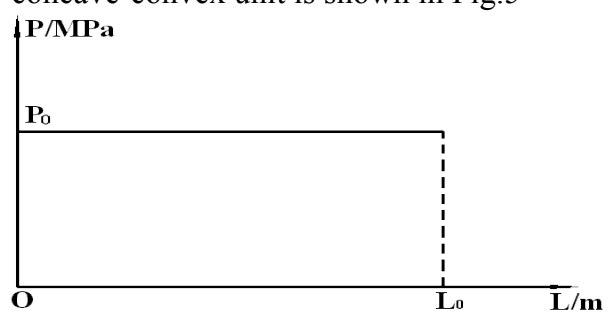

Fig.4 Carrying capacity of anchor in length direction

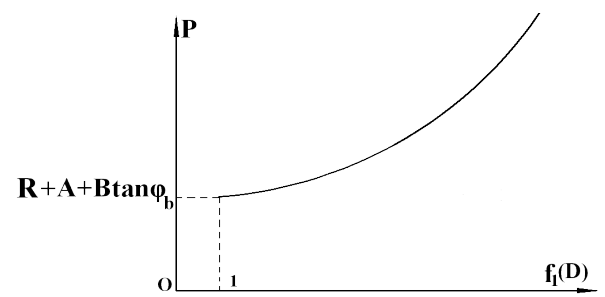

Fig.5 The relationship between bearing capacity and structural surface dimension

2) $J_{C S}>\sigma_{n}$

$P=R+\left(A+B \tan \left[\phi_{b}+J_{R C} \cdot \lg \left(J_{C S} / \sigma_{n}\right)\right]\right) \varepsilon^{1-D}$

On the basis of the analysis of the data, the bolt loading capacity nonlinearly increased with surface roughness.

(3) Hoop stress and radial stress analytic solution

Setting bolt inside micrometer and normal stress as $D_{1}$ and $p$ respectively. The stress boundary condition of bolt inner layer is listed as follows:

$$
\sigma_{\rho} /_{\rho=D_{1} / 2}=-p
$$

Setting bolt outside micrometer as D is listed as follows: $u_{\rho} /_{\rho=D / 2}=\frac{D_{1}-D}{2}$

The general solution of Plain strain axisymmetric problem is listed as follows:

$\sigma_{\rho} \approx \frac{A}{\rho^{2}}+2 C$

$\sigma_{\varphi} \approx-\frac{A}{\rho^{2}}+2 C$

$u_{\rho}=\frac{1+\mu}{E}\left[-\frac{A}{\rho}+2(1-2 \mu) C \rho\right]$

Applying formula (9)、 formula (10)、 formula (11) into formula (7)、 formula (8), The result we get shown as follows:

$A=-\frac{d^{2}}{4} \frac{G D\left(D_{1}-D\right)+2(1-2 \mu) D^{2} p}{d^{2}+(1-2 \mu) D^{2}}, C=\frac{G D\left(D_{1}-D\right)-d^{2} p}{2\left[d^{2}+(1-2 \mu) D^{2}\right]}$

Applying the formula that we get into formula formula (9), formula (10), formula (11), The result we get shown as follows:

$$
\begin{aligned}
\sigma_{\rho}= & -\frac{d^{2}}{4 \rho^{2}} \frac{G D\left(D_{1}-D\right)+2(1-2 \mu) D^{2} p}{d^{2}+(1-2 \mu) D^{2}}+\frac{G D\left(D_{1}-D\right)-d^{2} p}{d^{2}+(1-2 \mu) D^{2}} \\
\sigma_{\varphi}= & \frac{d^{2}}{4 \rho^{2}} \frac{G D\left(D_{1}-D\right)+2(1-2 \mu) D^{2} p}{d^{2}+(1-2 \mu) D^{2}}+\frac{G D\left(D_{1}-D\right)-d^{2} p}{d^{2}+(1-2 \mu) D^{2}} \\
u_{\rho}= & \frac{1+\mu}{E}\left[\frac{d^{2}}{4 \rho^{2}} \frac{G D\left(D_{1}-D\right)+2(1-2 \mu) D^{2} p}{d^{2}+(1-2 \mu) D^{2}}\right. \\
& \left.+\frac{(1-2 \mu)\left[G D\left(D_{1}-D\right)-d^{2} p\right] \rho}{d^{2}+(1-2 \mu) D^{2}}\right]
\end{aligned}
$$

\section{Bolt anchorage performance analysis}

\subsection{Radial anchoring effect of bolt in reinforcing} surrounding rock

The full grouted prestressed anchor can apply pressure to the surrounding rock so as to generate the effect of squeeze reinforcement and radial anchorage force and transform the stress states from unidirectional or bidirectional states to bidirectional or three-dircection states effectively. Through this way, the mechanic property parameter of the rock mass which was in the state of compression can be promoted. With time going on, this effect and the radial anchorage force can diffuse and fluctuate around continuously so as to improve the whole performance of the rock mass gradually.

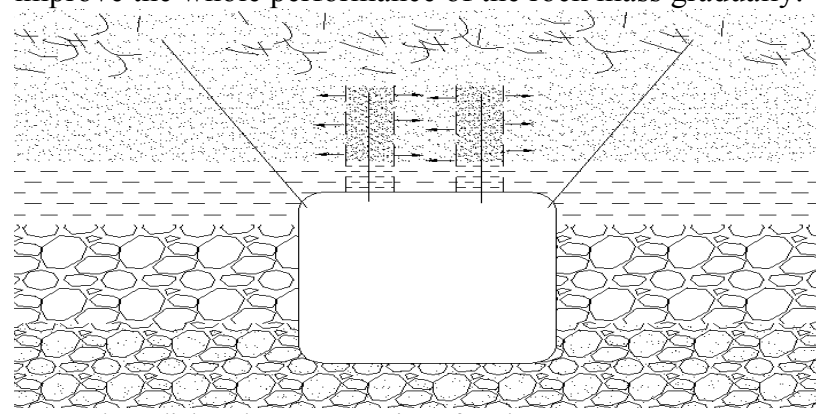

Fig.6 The radial anchorage operation of anchor 


\subsection{Tangential anchoring effect of bolt in reinforcing surrounding rock}

The tangential anchor force can play a great role in the aspects of improving the weak structural surface's shear strength and tension strength. The gap between the full grouted anchor and anchor pore will be missed through the expansion of the bolts body. Once the joint moves through the tangential direction, the anchor will be motivated. When the joint reaches its shearing strength, the anchor will be reached its maximum shear capability. The anchor's shearing capability is equivalent to the shearing strength's sum of the joint and anchor which makes the anchored rock mass's self-bearing ability improved significantly. The reinforcement role via squeeze and expansion makes the grouting bolt has higher surrounding rock's self-bearing ability than the full resin anchor and the better reinforcement effect.

\section{Anchorage force and anchorage parameters matching}

\subsection{Supporting anchor force and bolt tensile force matching}

The supporting anchor force is closely related with the bolt tensile force, they are both considered as radial anchorage force of roadway. And they should reasonably match each other. The bolt tensile force can be confirmed in accordance with the characteristics of surrounding rock and mine pressure. For the soft rock roadway, it has the characteristics of high mine pressure, large deformation and severe mine pressure behavior, so it should use full length anchoring bolt grouting, which can enhance the bolt tensile force and improve the force condition of bolt to fit the deformation of surrounding rock. The supporting anchor force can be ensured with the tensile capacity of bolt.

\subsection{Bolt shear force and characteristics of surrounding rock matching}

For the roadways with the development of joint, the development of stratification and severe mine pressure behavior, the deformation of the roadway are mainly induced by the dilatancy of the development of stratification. So, in order to control the large deformation failure along structural surface of surrounding rock, the flexible pressurized grouting bolt with high strength should be used to enhance the shear capacity and resist the deformation. For the roadways without the development of joint and stratification, the deformation failure of this roadways is radial deformation of roadway, so the bolt design is mainly to improve the bolt tensile force secondly to increase the bolt shear force.

6.3 The application and limitation of expansion anchorhold

The unique characteristic of the flexible pressurized grouting bolt is the expansion anchor-hold. Its action for surrounding rock need to be studied. But in the practice, adjusting the expansion anchor-hold should be made in the roadway supporting, or it will induce the collapse of the drill hole.

6.4 The option of anchor hole, injection pressure and diameter of bolt

Researches show that, the matching of drill hole, bolt body and injection pressure can improve bolt tensile force and bolt shear force, which can reduce the load of bolt plate induced by the deformation of surrounding rock. Compared with bolts with smaller diameter, the bolts with larger diameter have better adaptivity. So, for the option of bolt size, the bolts with large diameter should be used in the soft rock roadway with large estimated deformation.

\section{Conclusions}

(1)The working surface between bolt and anchoring surrounding rock possesses self-affine fractality characteristic, the shear strength nonlinearly increased with liquid injection pressure.

(2)When $\sigma_{n}$ is smaller than a constant value $q$, the working surface between loading layer and rock mass loses equilibrium and vice versa;

(3)When $J_{C S}$ is equal to $\sigma_{n}$, and fractal dimension keeps constant, the bolt loading capacity keeps invariability as it is along the length direction; when $\mathrm{J}_{\mathrm{CS}}<\sigma_{\mathrm{n}}$, the loading capacity nonlinearly increased with fractal dimension.

\section{Acknowledgments}

This work is supported by National Basic Research Program of China under Grant No.2012CB72310402, National Natural Science Foundation of China under Grant No.51244010 and No. 51304126, Science Research Innovative Group of College of Resources and Environmental Engineering of SDUST No.2012ZHTD06. New Teachers' Fund for Doctor Stations of Ministry of Education under Grant No.20123718120009. Open Project of State Key Laboratory Breeding Base for Mining Disaster Prevention and Control(Shandong University of Science and Technology) (MDPC2012ZR01). The research fund for excellent young and middle-aged scientists of Shandong Province under Grant No. 2013BSB01119.

\section{References}

1. LIAO Xiao-ping, WANG Hao, "Numerical analysis and field test on full grouted prestressed anchor", Chinese Journal of Rock Mechanics and Engineering 25(Suup), 2006, pp.3743-3747.

2. GU Lei-yu, XU Jing-mao, "Effect of geometric wave shape of anchor cable borehole wall on its bearing Capacity", Chinese Journal of Rock Mechanics and Engineering 24(20), 2005, pp.3771-3774.

3. ZHANG Jian-xin, LIU Li-min, "The effect of hole side roughness on the pile side resistance for cast-in-site piles", Geotechnical Investigation and Surveying (1), 2003, pp.13-15.
4. SHENG Jian-long, ZHU Rui-geng, "The Fractal Evaluation of Joint Roughness Coefficient", J. of Wuhan Uni. of Sci.\&Tech.(Natural Science Edition) 1(23), 2000, pp.1-3.

5. Mandelbrot B B., "The Fractal Geometry of Nature", San Francisco Freeman, San Francisco, America, 1982, pp.67-72.

6. CHEN Zhong-he, WANG Wei-qiang, "Analysis of anchoring mechanism of flexible inner pressured Bolt", Journal of Liaoning Technical University 25(5), 2006, pp.699-701.

7. Abdul-Wahed M K, Heib M A., "Senfaute G. Mining-induced seism city: Seismic measurement using multiple approach and numerical modeling", International Journal of Coal Geology 66(12), 2006, pp.137-147 
WEN Zhi-jie, ZHU Zhu-wu, Chen Lian-jun and Wen Jin-hao/

Journal of Engineering Science and Technology Review 7 (1) (2014) 15 - 20

8. Campanella,R.G., Weemees, I, "Development and use of an electrical resistivity cone for groundwater contamination studies", Canadian Geotechnical Journal 27 (5), 1990, pp.557 567.

9. Robertson, P. K., Campanella, R. G., Gillespie, D., and Rice,A., "Seismic CPT to measure in-situ shear wave velocity", Journal of Geotechnical Engineering 112 (8), 1986, pp.71 803.

10. Ferrero A M., "The shear strength of reinforced rock joints", Int. J.Rock Mech. Sci. and Geomech. Abstr 32(6), 1995, pp.595 605.

11. LI C, Stillborg B., “Analytical models for rock bolts”, Int. J. Rock Mech. Sci. and Geomech. Abstr 36(8), 1999, pp.1013 1 029.

12. Tang C A, Yang W T., "A new approach to numerical method of modelling geological processes and rock engineering problems continuum to discontinuum and linearity to nonlinearity", Engineering Geology 49, 1998, pp.207 214.

13. Hobst L, Zajic J, “Anchoring in rock and soil”, Elsever Scientific Publishing Company, New York, America, 1983, pp.78-81.

14. Eligehause R, Lehr B., "Behavior and design of anchorage with bonded anchors under tension load", International Conference on Anchoring \& Grouting towards the New Century, Guangzhou, China, 1999, pp.67-68.

15. Tang C A., "Numerical simulation on progressive failure leading to collapse and associated seismicity", International Journal of Rock Mechanics and Mining Science 34(2), 1997, pp.249 261.

16. WU Zhen-zhi, WANG Jian-jun, "Study on reasonable composite lining of multi-arch tunnel in shallow soft stratum", Journal of Highway and Transportation Research and Development 24(2), 2007, pp.94-98.

17. Shou K. J., "Three-dimensional hybrid boundary element method for non-linear analysis of a weak plane near an underground excavation", Tunneling and Underground Space Technology 15(2), 2000, pp.215-226.

18. STILL H, HOLMBERY M, NORD G., "Support of weak rock with grouted bolts and shotcrete", International Journal of Rock Mechanics and Mining Sciences 26(1), 1989, pp.99 113.

19. M. A. Hashem, M. N. Aimaghrabi, Modelling Mass Transfer Coefficients During Drop Formation 6(1), 2013, pp.7-13.

20. D. V. Sarafopoulos, "Twin-Double Layer Structure Producing Tailward Ion Jets in the Earth's Magnetosphere", Journal of Engineering Science and Technology Review 5(2), 2012, pp.76-84.

21. A. Sambas, M. Sanjaya W. S, M. Mamat., "Design and Numerical Simulation of Unidirectional Chaotic Synchronization and its Application in Secure Communication System". Journal of Engineering Science and Technology Review 6(4), 2013, pp.66-73.

22. Beck D A, Brady B H G., "Evaluation and application of controlling parameters for seismic events in hard-rock mines", International Journal of Rock Mechanics and Mining Sciences 39(5), 2002, pp.633-642.

23. Fujii Y, Ishijima Y, Deguchi G., "Predication of coal face rock burst and microseismicty in deep longwall coal mine", Int.J. Rock Mech. Min. Sci 34(1), 1997, pp.85-96.

24. Hanson D R, Vandergrift T L, "DeMarco M J, et al. Advanced techniques in site characterization and mining hazard detection for the underground coal industry", International Journal of Coal Geology 50(1-4), 2002, pp.275-301.

25. Ansell, A., "Laboratory testing of a new type of energy absorbing rock bolt", Tunn Undergr Space Technol 20, 2005, pp.291-300.

26. Hou Chaojong, "Review of roadway control in soft surrounding rock under dynamic pressure", Journal of Coal Science and Engineering 9(1), 2003, pp.1-7.

27. Kidybinski A., "Bursting liability indices of coal", International Journal of Rock Mechanics and Mining Sciences 18, 1981, pp.295304.

28. Wen, Z.J., "Study of stress features of fully grouted prestressed anchors", Ro. \& So. Mech 31, 2010, pp.177-181.

29. Malan D F., "Simulation of the time-dependent behavior of excavations in hard rock", Rock Mech Rock Eng 35(4), 2002, pp.225-254.

30. Wang Weixing, Jin Wenbiao, Huang Xing, "Rock fracturing tracing by image processing", Journal of Fudan University (Natural Science) 43(5), 2004, pp.930-933.

31. Huang Q, Angelier J., "Fracture spacing and its relation to bed thickness", Geological Magazine 4(126), 1989, pp.355-362. 